\title{
Separations and Actinide Science - 2005 Roadmap
}

\author{
Michael Mcllwain
}

September 2005

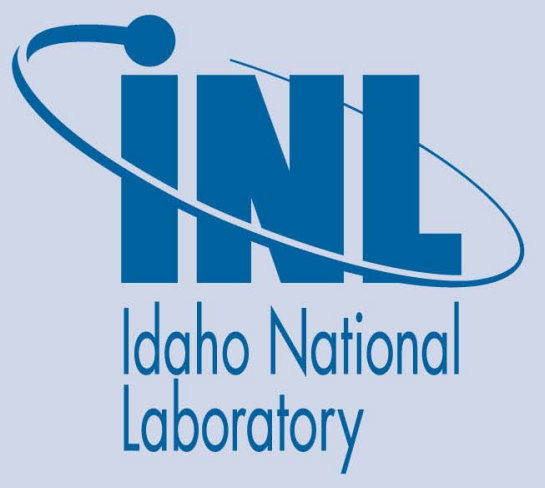

The INL is a U.S. Department of Energy National Laboratory operated by Battelle Energy Alliance 
INL/EXT-05-00762

\section{Separations and Actinide Science - 2005 Roadmap}

Michael Mcllwain

September 2005

\section{Idaho National Laboratory \\ Idaho Falls, Idaho 83415}

Prepared for the

U.S. Department of Energy

Office of Nuclear Energy

Under DOE Idaho Operations Office

Contract DE-AC07-05ID14517 


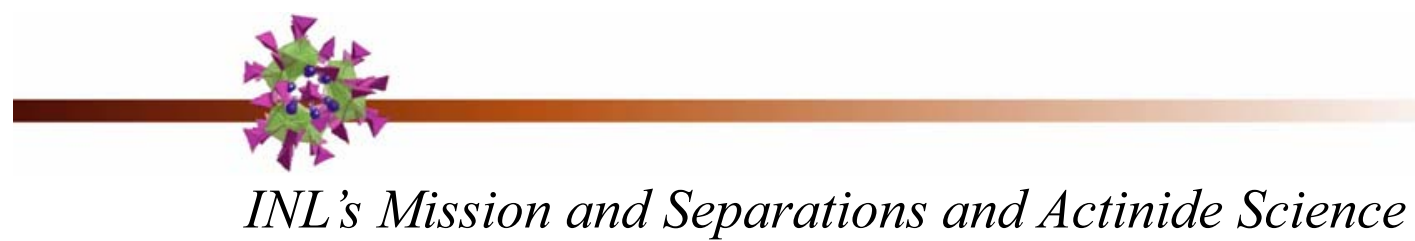

The Separations and Actinide Science Roadmap presents a vision to establish a separations and actinide science research (SASR) base composed of people, facilities, and collaborations and provides new and innovative nuclear fuel cycle solutions to nuclear technology issues that preclude nuclear proliferation. This enabling science base will play a key role in ensuring that Idaho National Laboratory (INL) achieves its long-term vision of revitalizing nuclear energy by providing needed technologies to ensure our nation's energy sustainability and security. To that end, this roadmap suggests a 10-year journey to build a strong SASR technical capability with a clear mission to support nuclear technology development.

If nuclear technology is to be used to satisfy the expected growth in U.S. electrical energy demand, the once-through fuel cycle currently in use should be reconsidered. Although the once-through fuel cycle is cost-effective and uranium is inexpensive, a once-through fuel cycle requires long-term disposal to protect the environment and public from long-lived radioactive species. The lack of a current disposal option (i.e., a licensed repository) has resulted in accumulation of more than 50,000 metric tons of spent nuclear fuel.

The process required to transition the current once-through fuel cycle to full-recycle will require considerable time and significant technical advancement. INL's extensive expertise in aqueous separations will be used to develop advanced separations processes. Computational chemistry will be expanded to support development of future processing options.

In the intermediate stage of this transition, reprocessing options will be deployed, waste forms with higher loading densities and greater stability will be developed, and transmutation of long-lived fission products will be explored. SASR will support these activities using its actinide science and aqueous separations expertise.

In the final stage, full recycle will be enabled by advanced reactors and reprocessing methods based on pyrochemical methods and by using different fuel cycles that do not readily produce plutonium. SASR will facilitate the deployment of advanced pyrochemical separation technology and support development of reprocessing of thorium-based reactor fuels.

\section{Development of a separations and actinide science capabil- ity at INL will provide an important and necessary component in the develop- ment of a sustainable nuclear fuel cycle for the nation.}


INL faces challenges to develop capabilities for solving fuel cycle issues. SASR capabilities at INL and the entire domestic technical community are in decline and use aging facilities. Few institutions have the unique facilities and technical talents needed to perform the necessary research and development activities. With exception of the weapons laboratories, those domestic institutions that do have limited capacity to perform this research have old and outdated facilities. INL urgently needs new facilities to perform laboratory research and process development, since the few available facilities are slated to be decommissioned in a few years. Strategies that augment SASR staff and that resolve INL facility issues are offered in this roadmap.

Fostering national and international collaboration will help to jump-start and fortify SASR activities, provide access to a substantial knowledge base and specialized research tools, and provide current and future staff with development opportunities. Strategies to promote these needed collaborations are presented.

The success of the program presented in this roadmap depends on a long-term commitment to develop staff, facilities, and collaborations. Funding is needed at INL for both basic and applied research activities directed at the technical issues associated with the fuel cycle and resolution of proliferation concerns. This roadmap provides strategies to obtain this funding.

This roadmap makes three recommendations related to programmatic actions that must occur to renew domestic SASR capabilities:

- Department of Energy Office of Nuclear Energy (NE) should develop an applied research program at INL to create a knowledge base for new fuel cycle technologies

- Nuclear Engineering Research Initiative (NERI) program needs to be revamped and redirected to support applied research in the external research community

- A nuclear energy basic science program, with shared management between the Offices of Science (SC) and Nuclear Energy and modeled after Environmental Management Science Program (EMSP), should be created to address long-term technical issues and to foster training of the future generation of nuclear technology scientists and engineers.

Development of a SASR capability at INL will provide an important and necessary component in the development of a sustainable nuclear fuel cycle for the nation. 


\section{CONTENTS}

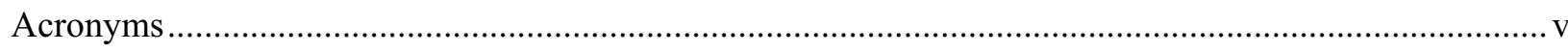

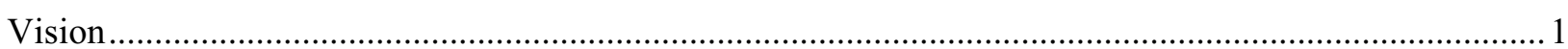

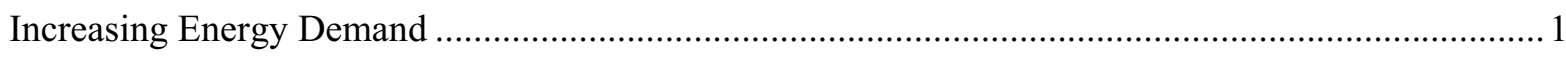

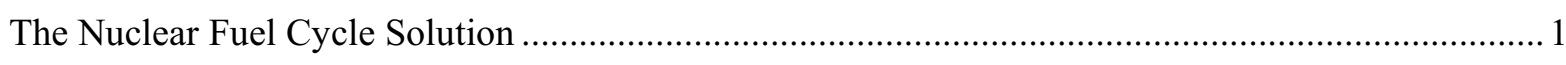

General Approach To Transition To Spent Fuel Recycling................................................................ 3

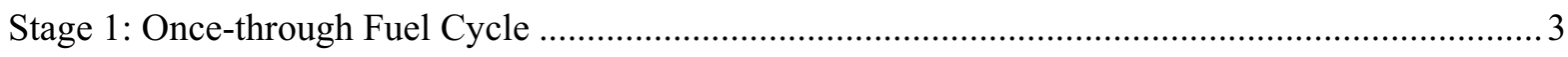

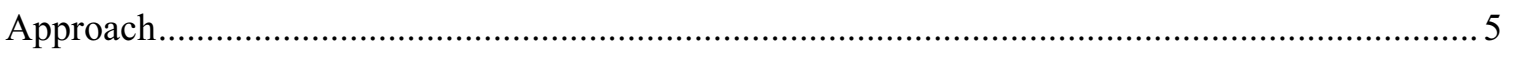

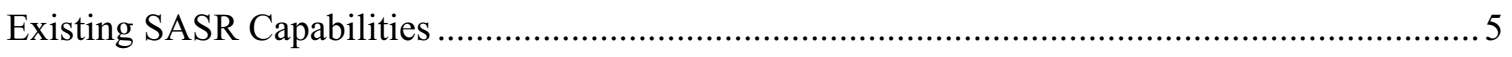

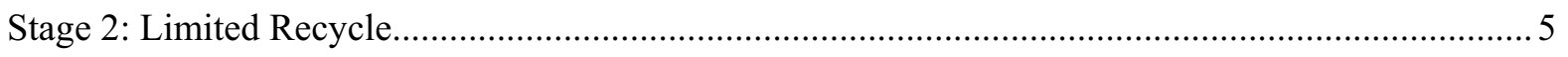

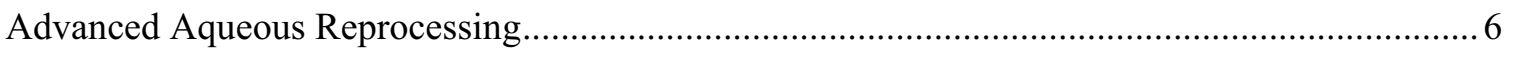

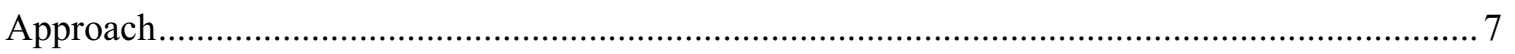

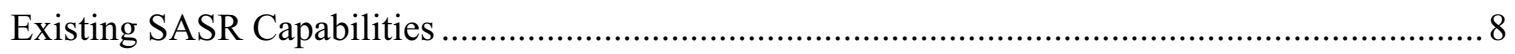

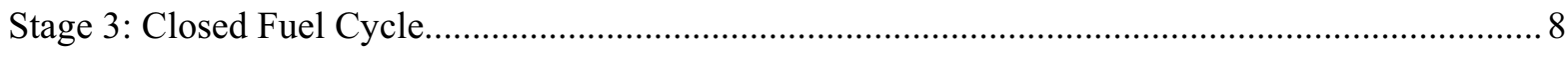

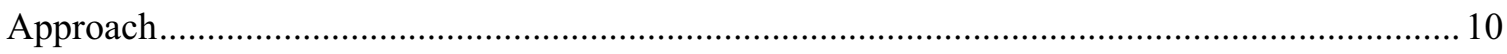

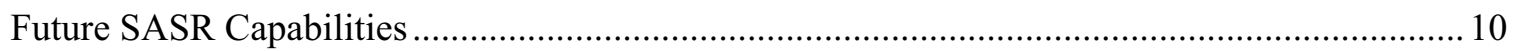

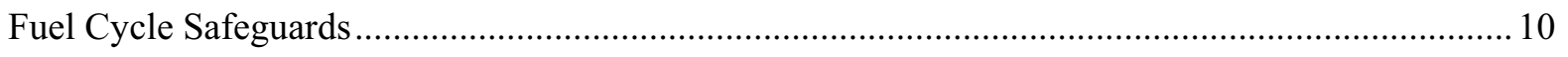

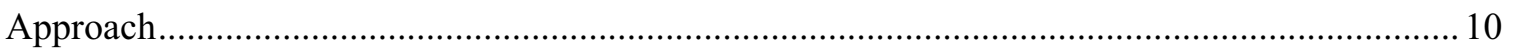

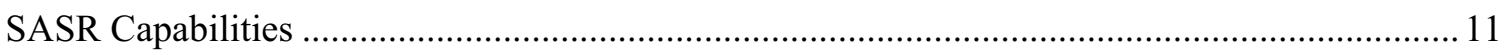

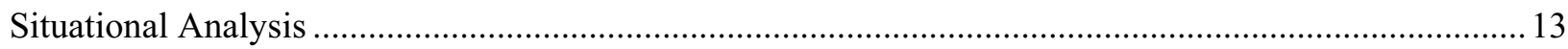

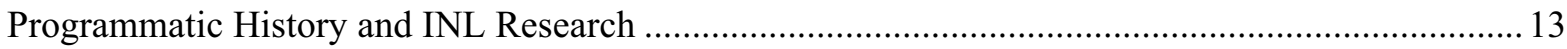

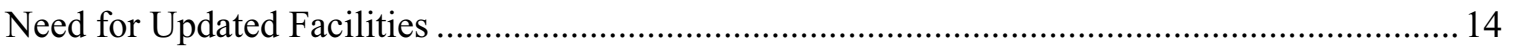

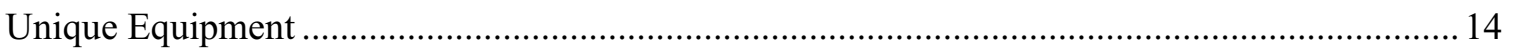

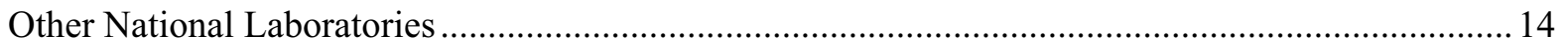

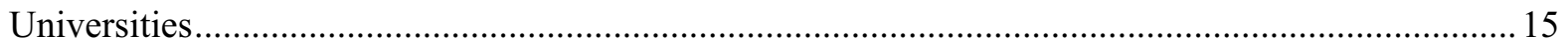

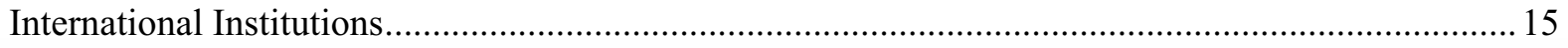

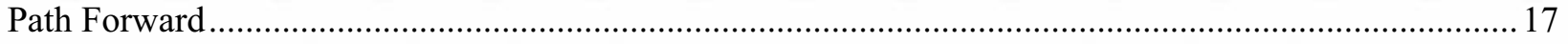

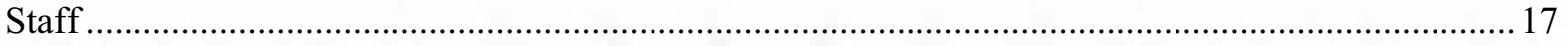

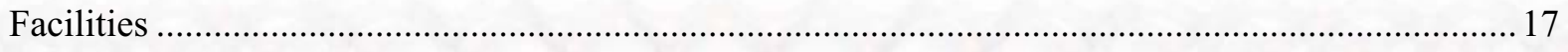

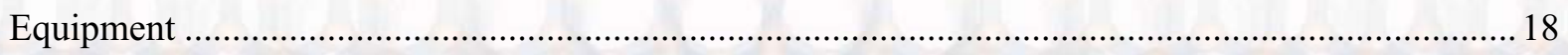

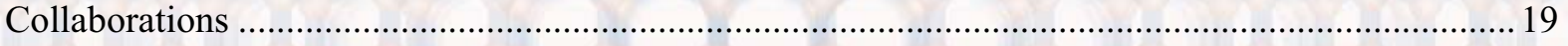

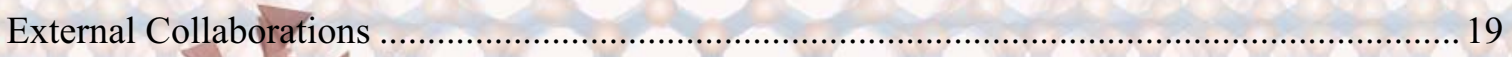

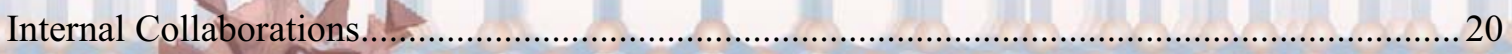


iv

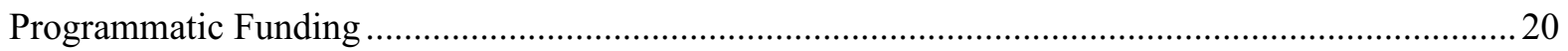

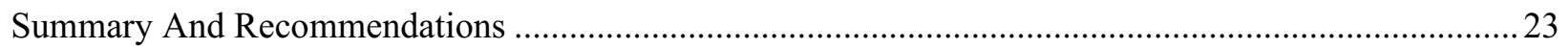

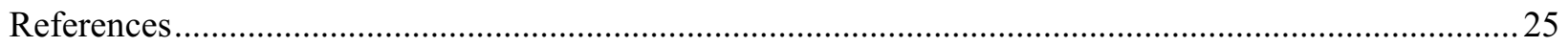

\section{FIGURES}

1. The Separations and Actinide Science vision enables a sustainable nuclear energy fuel cycle.............2

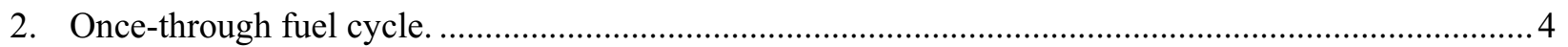

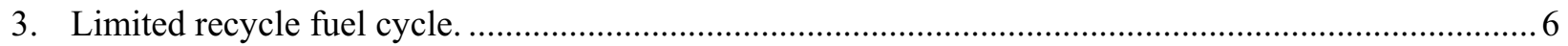

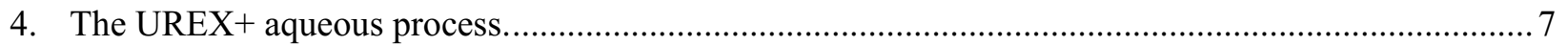

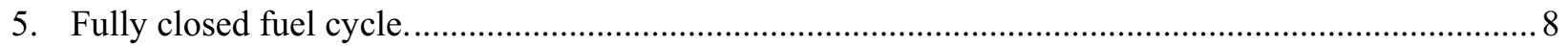

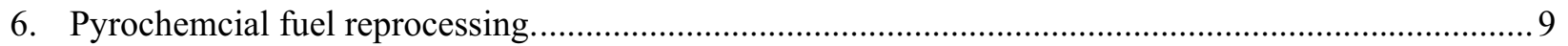

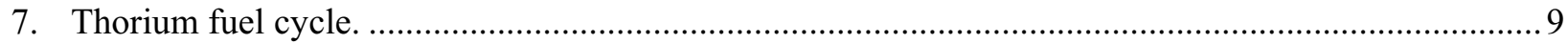

8. Separations and actinide chemistry capabilities across the DOE complex. ..................................... 15

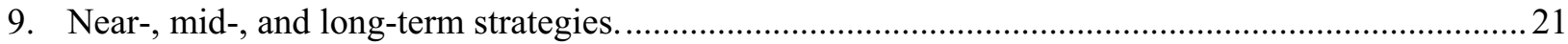




\section{ACRONYMS}

$\begin{array}{ll}\text { AFCI } & \text { Advanced Fuel Cycle Initiative } \\ \text { CAMS } & \text { Center for Advanced Modeling and Simulation } \\ \text { EBRII } & \text { Experimental Breeder Reactor II } \\ \text { EM } & \text { Office of Environmental Management } \\ \text { EMSP } & \text { Environmental Management Science Program } \\ \text { FR } & \text { fast spectrum reactor } \\ \text { INL } & \text { Idaho National Laboratory } \\ \text { IRC } & \text { INL Research Center } \\ \text { MFC } & \text { Materials and Fuel Complex } \\ \text { NE } & \text { Department of Energy Office of Nuclear Energy } \\ \text { NERI } & \text { Nuclear Engineering Research Initiative } \\ \text { NESP } & \text { Nuclear Energy Science Program } \\ \text { PUREX } & \text { Plutonium-Uranium Extraction } \\ \text { RTC } & \text { Reactor Technology Complex } \\ \text { SASR } & \text { Separations and Actinide Science Research } \\ \text { SC } & \text { Office of Science } \\ \text { THOREX } & \text { process for separating uranium-233 from irradiated thorium } \\ \text { UNLV } & \text { University of Las Vegas } \\ \text { UREX+ } & \text { fuel reprocessing project proposed by European Nuclear Energy Association }\end{array}$




\section{Separations and Actinide Science}

\section{VISION}

In order to secure a strong economic future, the U.S. needs a sustainable energy source. Nuclear technology has the potential to meet this need for the nation. However, if the potential of nuclear energy is to be realized, the once-through fuel cycle practiced for decades must be reconsidered. The cycle requires long-term disposal to protect the environment and public from long-lived radioactive species. Until a national repository is opened, spent nuclear fuel will continue to accumulate - currently more than 50,000 metric tons.

Significant challenges revolve around the issues associated with the nuclear fuel cycle ${ }^{1}$. Without an appropriate fuel cycle, nuclear energy will not be sustainable. Additionally, selected fuel cycles must be proliferation resistant ${ }^{2-5}$; thus, the technical challenges associated with fuel cycles are substantial.

To address these scientific and technical challenges by 2015, the Separations and Actinide Science vision is to establish a nuclear technology science base composed of people, facilities, and collaborations to:

- Underpin the development of an advanced fuel cycle with improved economics

- Provide inherently safe high-temperature fuels

- Eliminate the potential production of nuclear weapons through reprocessing of spent fuel

- Permit environmentally safe management of the associated waste.

\section{Increasing Energy Demand}

The U.S. is the leading energy consumer in the world, and our economic growth depends on having readily available and affordable energy resources. Similarly, other growing economies, especially those of India and China, need energy. Increased demand for available energy resources will impact cost and availability of some fuels, primarily petroleum and natural gas, and force the U.S. to use other fuels for electricity production.

Coal is the primary fuel used for electricity production, but burning coal and other fossil fuels releases carbon dioxide in the atmosphere. Growing evidence has linked increased atmospheric carbon dioxide with global warming. If this evidence proves to be true, the U.S. and the global community will need to greatly reduce the amount of carbon dioxide released to the atmosphere in order to avoid altering the environment. To that end, nuclear technology, specifically nuclear electricity production, produces electric power with no carbon dioxide emissions.

\section{The Nuclear Fuel Cycle Solution}

A sustainable fuel cycle requires developmental activities in several areas. A once-through fuel cycle, as practiced by the U.S., has resulted in more than 50,000 metric tons of spent nuclear fuel. A geologic repository is proposed as a safe way of disposing of this material, but the proposed repository will only accommodate the spent fuel produced by the current fleet of nuclear reactors. If the U.S. continues to employ a once-through fuel cycle and adds additional power reactors, a single repository will not meet the national needs.

Actinides are a significant factor in repository analyses. Thus, by eliminating actinides that require disposal with spent nuclear fuel, the radiotoxicity of the waste is reduced. Additionally, reducing the 
long-lived actinides simplifies the fate and transport analysis and eliminates the need to calculate doses for hundreds of thousands of years.

A new, efficient generation of nuclear reactors exists and is being constructed and operated in other parts of the world. These advanced reactors, with closed fuel cycles, permit actinide and other radio isotopic separations for recycling and transmutation and reduce the need for additional repositories.

The preceding discussion dictates that the once-through fuel cycle be reconsidered and a more sustainable fuel cycle be employed to support future growth of nuclear energy (see Figure 1). INL has existing capabilities that can be used to address the current problems with nuclear fuel cycle. An enhanced INL Separations and Actinide Science capability will be critical to completing the transition to an advanced fuel cycle.

Technical Needs and Challenge

\section{Idaho National Laboratory Separa- tions and Actinide Science Contribu- tions}

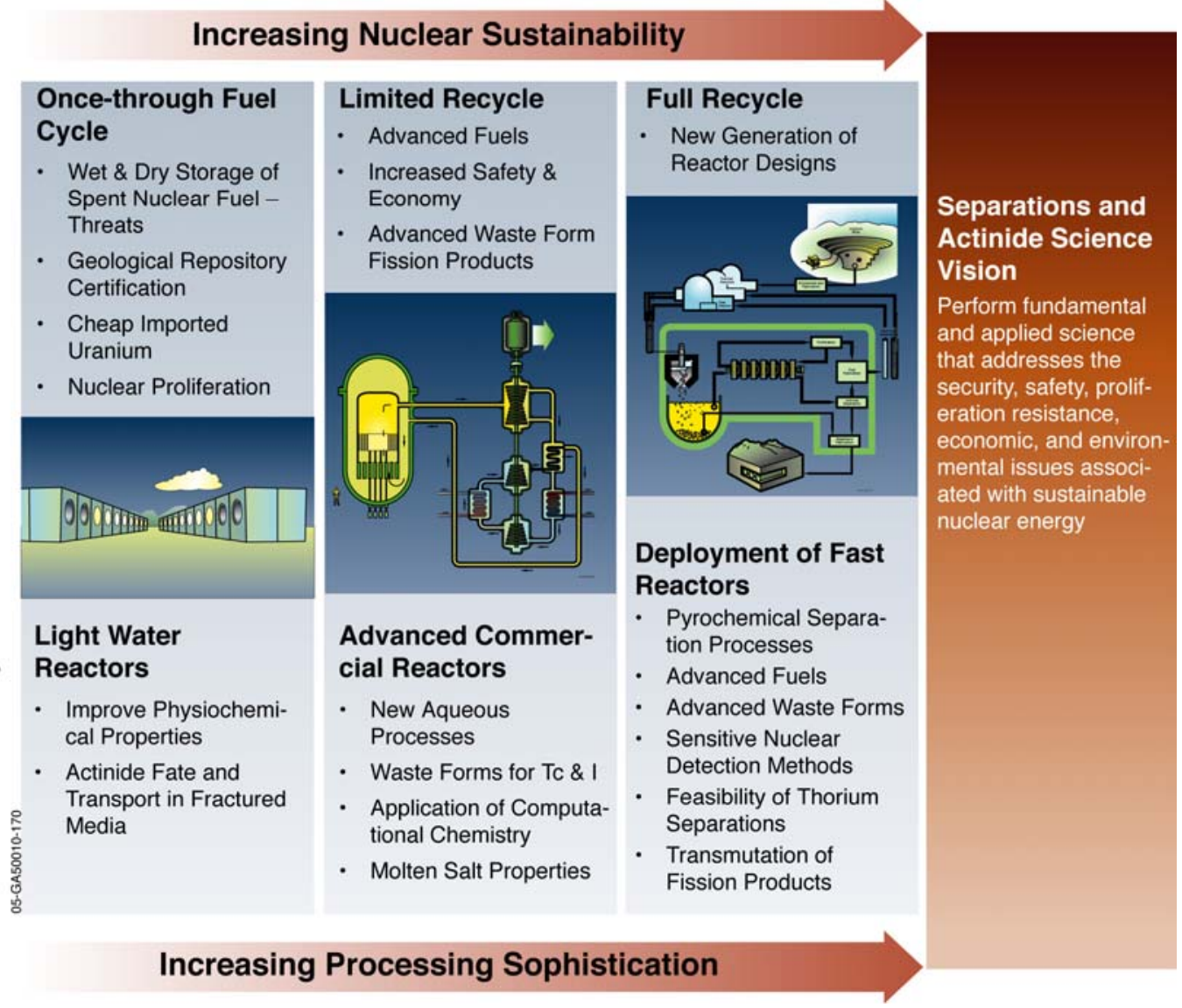

Figure 1. The Separations and Actinide Science vision enables a sustainable nuclear energy fuel cycle. 


\section{GENERAL APPROACH TO TRANSITION TO SPENT FUEL RECYCLING}

The general approach to transition to spent fuel recycling has three steps:

- Restart reprocessing of spent fuel

- Pave the way for the future fuel cycle with fundamental and applied research

- Create and deploy new technologies to effectively use uranium and plutonium resources.

The transition from a once-through fuel cycle to a closed fuel cycle will require a staged approach and substantial private and federal investment. Figure 1 pictorially represents the transition from a once-through fuel cycle to a closed fuel cycle.

There are three stages to this transition, which follows the strategy laid out in the Advanced Fuel Cycle Initiative (AFCI) roadmap. ${ }^{7}$

- In stage 1, most of the focus is on restoring reprocessing of spent fuel and modifying existing aqueous based schemes to supply proliferation resistant reprocessing technologies needed in the intermediate stage 2 .

- Stage 2 focuses on the recycle of plutonium and certain actinides and environmentally safe disposal of other fission products. Increased efficiency requirements will drive the need for advanced nuclear reactor fuels having enhanced burn up potential with inherent safety.

- Stage 3 focuses on achieving a closed fuel cycle with actinide transmutation in which all fissile and fertile materials are recycled. Efficient separation schemes permit segregation of the lanthanides in the geologic repository and low-level disposal of the remaining fission products. The reactor fleet at Stage 3 contains a contingent of fast reactors that are capable of actinide transmutation.

A closed fuel cycle eliminates the disposal of uranium and plutonium as it can be recycled for energy production. As a direct benefit, the demand for geologic repository space is dramatically reduced by not disposing of uranium. The uranium resource is more efficiently used due to higher efficiency reactors and recovery of energy value from spent fuel.

\section{Stage 1: Once-through Fuel Cycle}

The once-through fuel cycle, as displayed in Figure 2, was implemented in the U.S. for the following reasons:

- Proliferation concerns associated with the Plutonium-Uranium Extraction (PUREX) process led the U.S. to end fuel reprocessing 


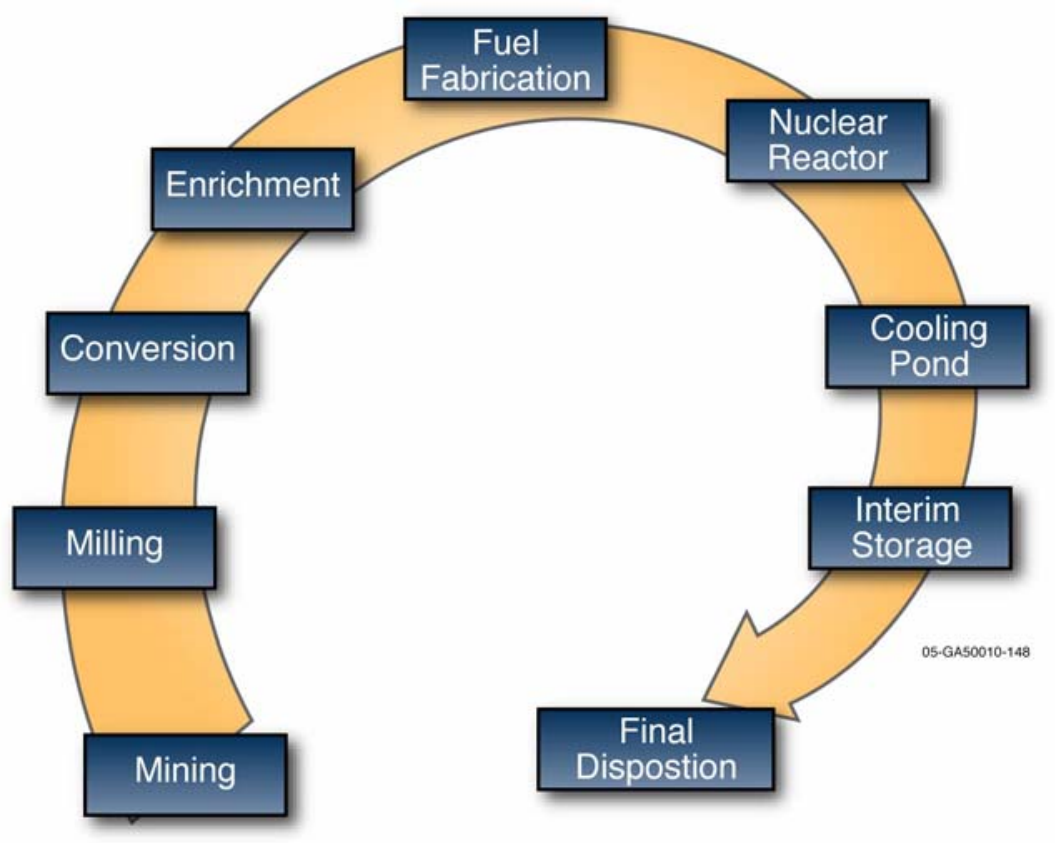

Figure 2. Once-through fuel cycle.

- Based on current price and availability of uranium ore, once-through is the lowest cost option

- Fuel fabrication can be performed directly without significant radiation exposure to the workers

- Near-term proliferation resistance is provided by the high radioactivity and a requirement for unique and sophisticated remote handling and processing operations

- Wet and dry storage of spent fuel is a reasonably safe and lost-cost option.

The primary disadvantage of a once-through fuel cycle is the need to have very long-term isolation. This need arises from the fact that spent fuel contains a number of very long-lived radioactive species. These species are primarily actinide elements with life-times greater than 10,000 years. The performance standard developed by the U.S. Environmental Protection Agency and enforced by the Nuclear Regulatory Commission requires rigorous performance assessment modeling by DOE to demonstrate compliance. The modeling, that predicts radionuclide fate and transport, is completed by the repository site and represents the site's domains of low transport (rock) with widely disposed high transport (fractures). Performing these analyses over geologic time scales is difficult. Defending the results in a public forum is more challenging.

Although there is a need for monitoring the fuel cycle for the attributes and signatures of proliferate activities, ${ }^{6,8}$ other countries do reprocess spent fuel to recover plutonium. These reprocessing activities are based on the PUREX process developed for nuclear weapons production. The recycled plutonium that is produced has low radioactivity and does not pose significant risks to workers making, handling, and loading reactor fuel. Mixed oxide fuel (uranium and plutonium) produced following reprocessing can be used to power the existing fleet of light water reactors. ${ }^{9}$ The separation technology is well proven and capable of high processing rates. However, proliferation is a significant concern, since the PUREX process produces a pure plutonium product. In addition, mixed oxide fuel is, itself, a proliferation issue. The neutron spectrum of a light water reactor is such that it produces about as much plutonium as was in the original fuel. The mixed oxide fuel initially contains about $7 \%$ plutonium by weight, and has about 1 to $4 \%$ plutonium in the spent fuel. 


\section{Approach}

To address the near-term issues associated with the once-through fuel cycle and proliferation, the following will be undertaken:

- Address issues associated with the existing reprocessing schemes by development of alternative aqueous separations routes

- Address issues with the existing reprocessing schemes by development of denaturing concepts so that the existing reactor and power plutonium grades cannot be used for weapons

- Begin to develop new reprocessing strategies by developing computational chemistry approaches to aid in the development of new separation processes

- Support geologic repository performance conformation by deployment of enhanced modeling methods that predict transport of radionuclides in fractured media

- Support geologic repository performance confirmation by using state-of-the-art instrumenting methods; determination of the physiochemical transport properties will be determined at the necessary accuracy needed for improved repository characterization

- Enhance proliferation detection by rapid deployment of high sensitivity instrumentation currently under development and proceed to develop concepts for even more sensitive instrumentation.

\section{Existing SASR Capabilities}

- INL has over 40 years of experience in the development of radionuclide separations in acidic, aqueous media and full-scale reprocessing of difficult-to-process fuel types (e.g. aluminum, zirconium, stainless steel, and graphite). This acidic aqueous expertise is unique to INL.

- INL has, over the last five years, developed a very strong capability in subsurface science. One of the strengths of this capability is relevant research and computational modeling of transport through fractured media. This capability can be rapidly mobilized to assist in modeling of the fate and transport of actinides to be stored in a geologic repository.

- INL has developed a number of unique instruments for characterization of species on surfaces. Due to the high sensitivity of these instruments, determinations of various transport properties can be made with very high precision and accuracy. These methods are ideally suit to the determination of actinide transport properties.

- INL has published extensively on the topic of actinide binding to soils and minerals and has on-going research related to removal of actinides and other radionuclides from various types of mineral and structural materials. The experimental extraction techniques used in these studies could also be employed for determination of physiochemical transport properties.

- INL has used computational chemistry to understand the fate and transport of species in environmental settings and has used various types of models to predict the structure and composition of species in aqueous solutions typical of environmental settings. This computational chemistry capability can be easily applied to aid in the development of advanced extractants and to understand the dynamics occurring in separation processes.

\section{Stage 2: Limited Recycle}

Figure 3 displays the limited recycle concept for advanced commercial reactors used in Stage 2. The limited cycle is based on processes that recycle transuranic elements repeatedly until they are destroyed. Long-lived fission products go to the geologic repository. Uranium and short-lived fission products go to low-level disposal. 


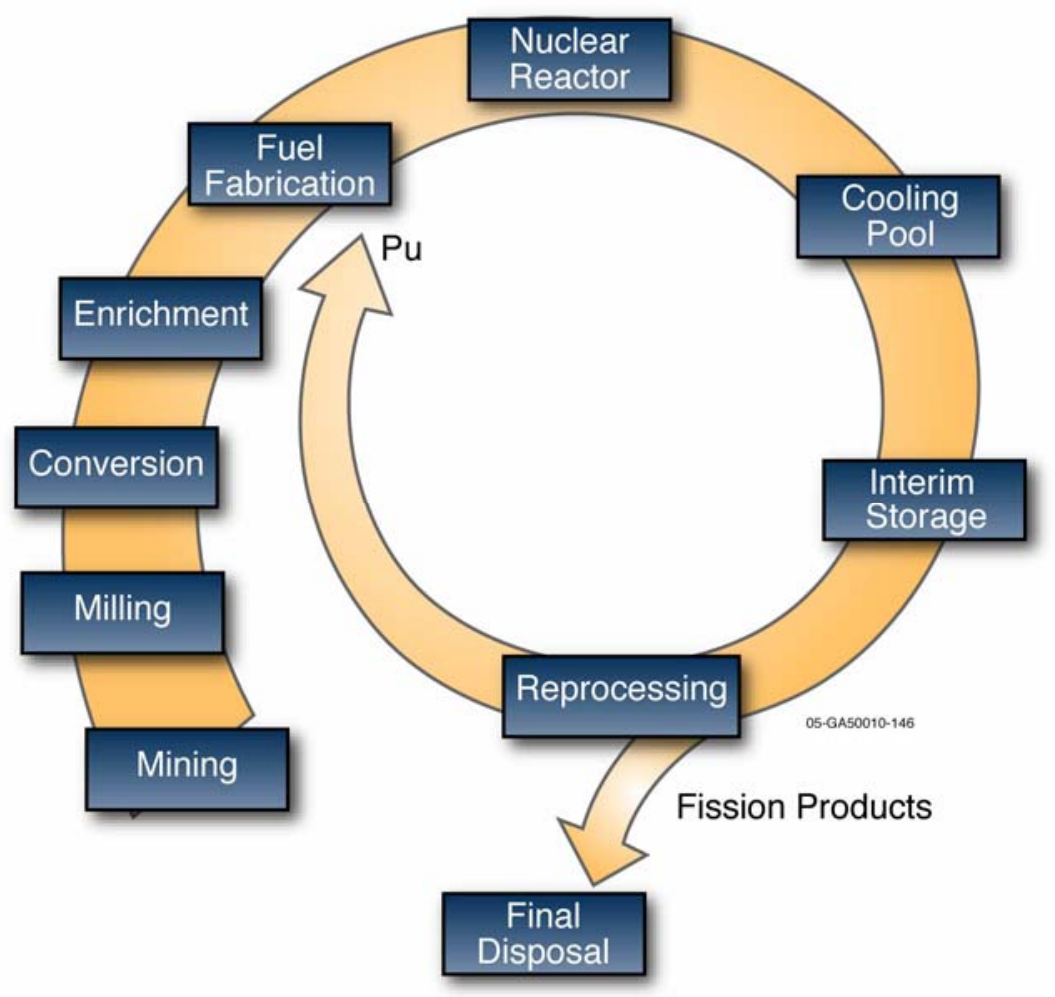

Figure 3. Limited recycle fuel cycle.

Stage 2 advanced commercial reactor concepts will be more efficient and safer than the existing fleet of nuclear reactors. These advanced reactor concepts will use advanced fuels that can tolerate higher burn up, maybe as high as $100 \mathrm{GWd} / \mathrm{t}^{\mathrm{a}}$, without concern for the integrity of the fuel. Mixed oxide fuels will power these new reactors. These new fuels will have inherent safety features to ensure that off-normal events will not lead to fuel integrity issues. Fuel reprocessing based on an aqueous processing scheme will have been implemented. The oldest material in the spent fuel inventory will have been reprocessed. To accommodate the waste produced by reprocessing, new waste forms will be deployed to handle the different waste species and to enhance the loading density of waste per unit of waste form. A geologic repository will have been certified, and waste from reprocessing will begin to be stored in the repository.

As we transition from limited recycle to a fully closed cycle, a limited number of fast spectrum reactors (FR) need to be commissioned for transmutation.

\section{Advanced Aqueous Reprocessing}

Several advanced reprocessing schemes have been proposed to replace the PUREX process. The fuel reprocessing project proposed by European Nuclear Energy Association (UREX+) aqueous process is currently the leading candidate. ${ }^{10}$ The process is shown schematically in Figure 4 and produces a uranium product that can be disposed of as a Class $\mathrm{C}^{\mathrm{b}}$ low-level waste. The plutonium and other transuranic species are never separated. Cesium and strontium are separated and disposed of as greater than Class $\mathrm{C}$ low-level waste. The lanthanides are immobilized into an advanced waste form and disposed of in the geologic repository. This process never produces a pure plutonium product, and with the addition of the

a. gigawatt day per ton(metric)

b. Class C low-level waste has the highest concentration of radioactive material allowed to be buried in a low-level waste disposal facility. 
other actinides, has greater proliferation resistance due to the radioactivity of the added actinides. The performance of the geologic repository is greatly improved by substantial reduction of the volume of waste requiring repository disposal. Further, the half-life of the species being stored in the repository is less than 1000 years, instead of greater than 10,000 years. This also impacts the performance of the geologic repository.

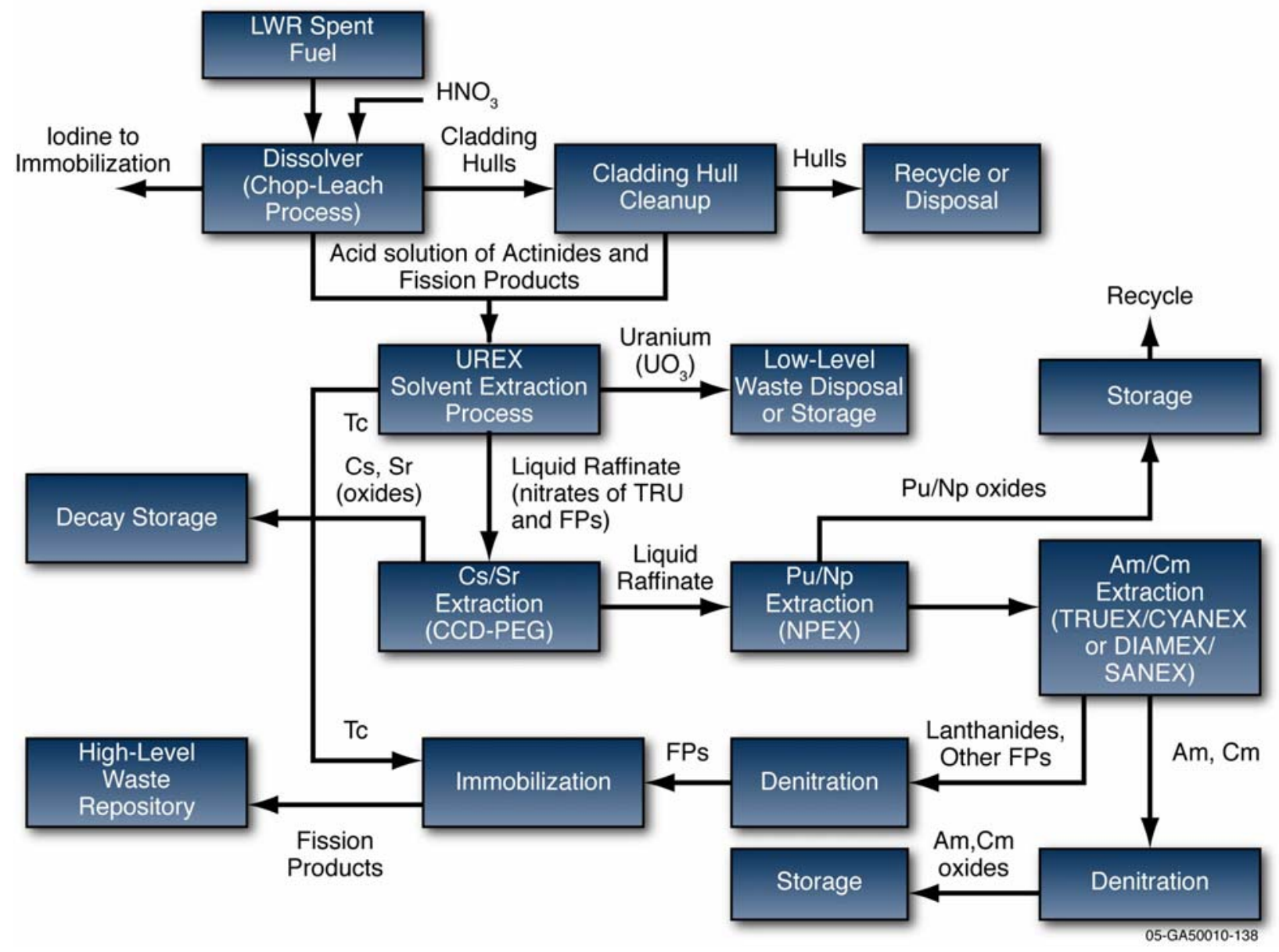

Figure 4. The UREX+ aqueous process.

The limited recycle, or transitional recycle, has a number of disadvantages that must be addressed. The increased radioactivity of the plutonium requires that the resulting mixed oxide fuel be remotely assembled, which substantially increases the price of fuel. The process has many streams and is highly complex. This complexity will require a significant amount of redundancy and process control that dramatically increase the plant costs. Currently, there is no efficient process for separation of lanthanides from actinides. In this transitional recycle scheme, the long-lived fission products, technetium and iodine, must be disposed of in the geologic repository. There are no waste forms available for these species.

\section{Approach}

- Deploy the UREX+ process with greater separation efficiency and improvements associated with separation of lanthanides and actinides

- Develop waste forms for technetium and iodine

- Examine transmutation routes for destruction of technetium and iodine 
- Extend pyrochemical separation methods to processing of oxide fuels to either augment or replace aqueous processing

- Employ computational chemistry to direct process development and to solve process problems.

\section{Existing SASR Capabilities}

- INL has over 40 years of experience in the development of radionuclide separations in acidic, aqueous media and full-scale reprocessing of difficult-to-process fuel types (e.g. aluminum, zirconium, stainless steel, and graphite). This acidic aqueous expertise is unique to INL.

- INL has processed metallic spent fuel using pyrochemical and molten salt electrochemical methods.

- INL has performed extensive research in advanced waste forms to support environmental management and processing of metallic fuel.

- INL has a demonstrated ability to develop or synthesize unique organic materials and has extended this capability to prepare new complexing materials.

\section{Stage 3: Closed Fuel Cycle}

The fully closed fuel cycle does not differ significantly from the limited recycle, and is shown in Figure 5. The primary difference is that the uranium is recycled and the long-lived fission products are transmuted. This ultimate fuel cycle incorporates a new generation of reactor concepts that use very advanced fuel and operate at temperatures greater than $800^{\circ} \mathrm{C}$. This fleet of new reactors will be a combination of fast spectrum reactors and accelerator-driven reactors that complement the advanced commercial reactors deployed during stage 2 .

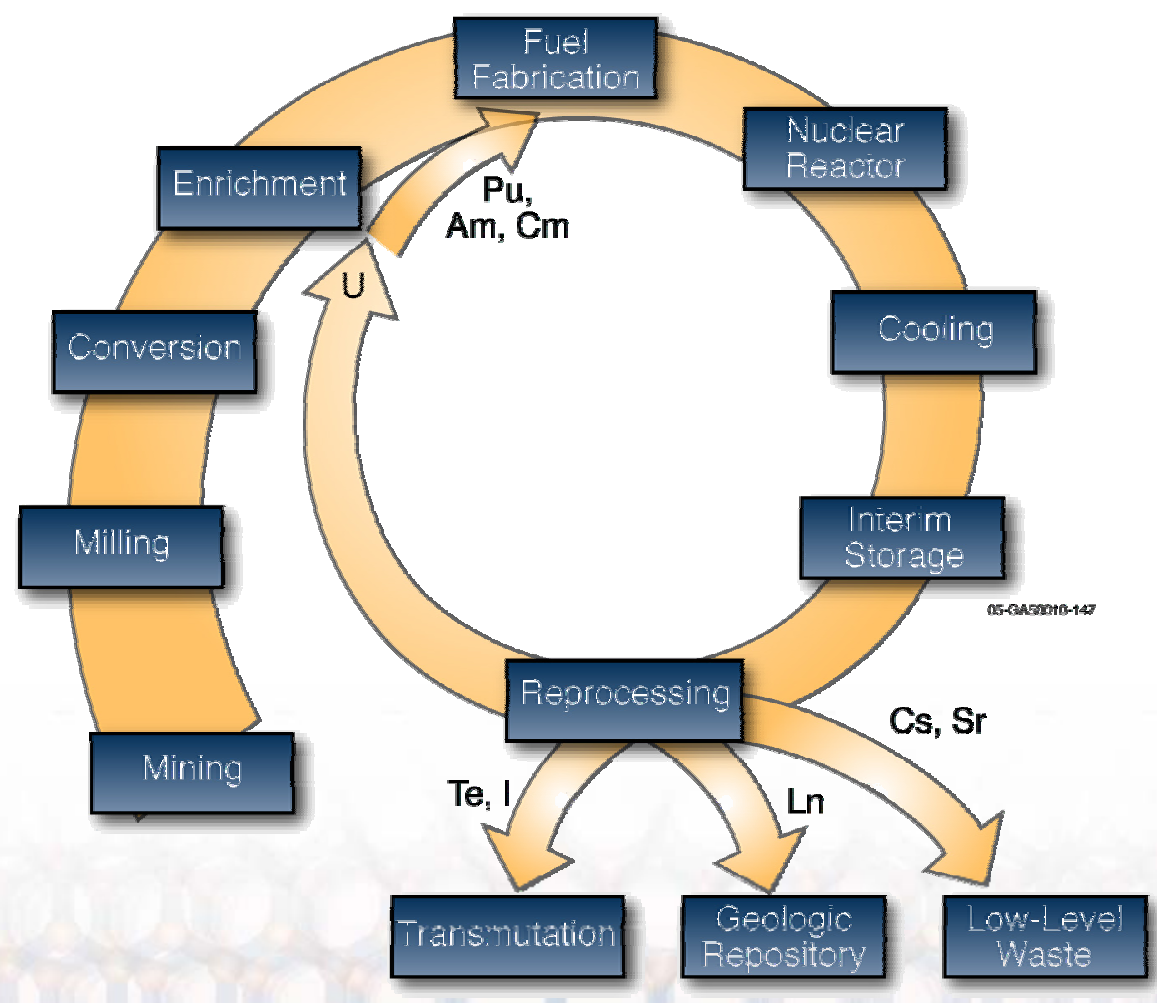

Figure 5. Fully closed fuel cycle. 


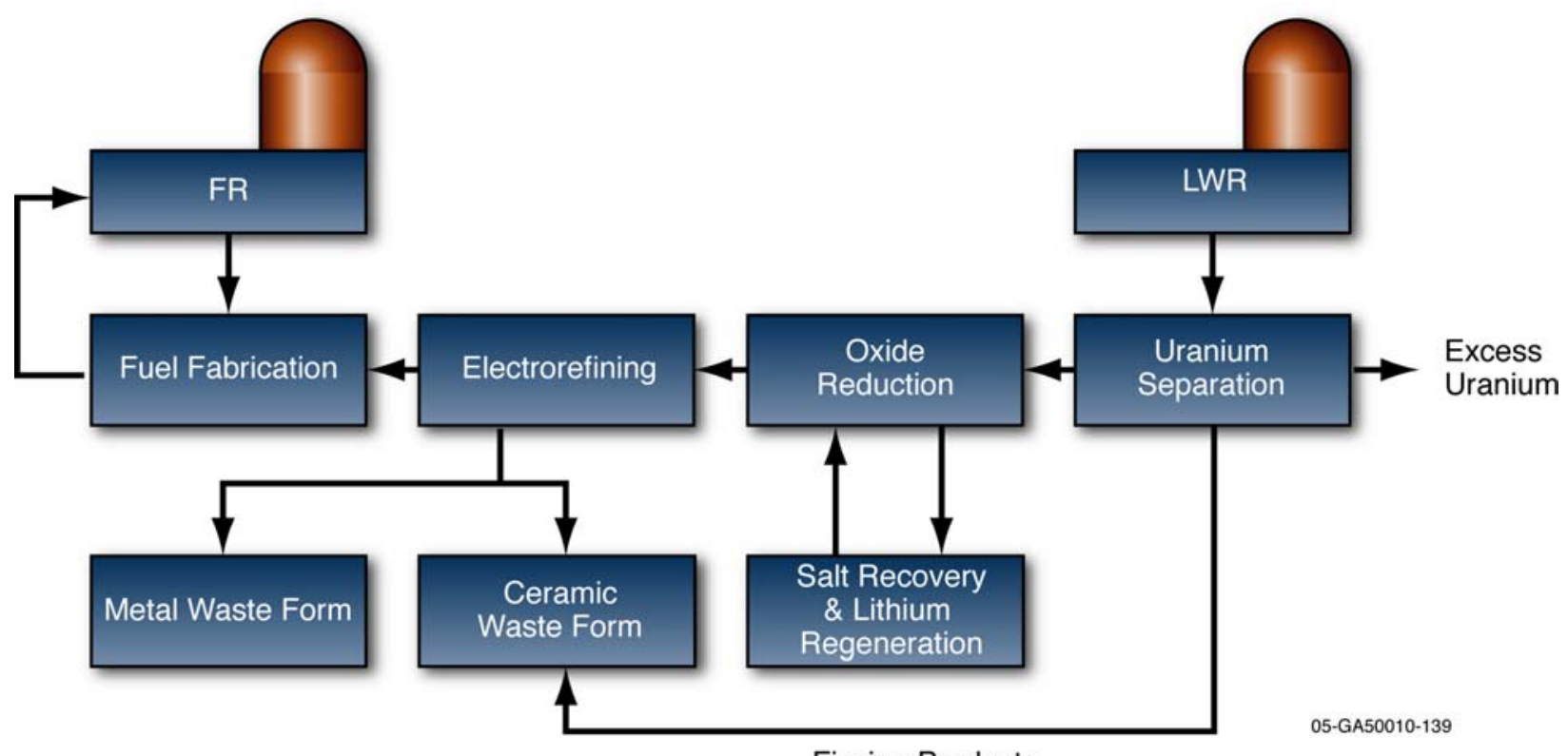

Fission Products

Figure 6. Pyrochemcial fuel reprocessing.

During stage 3 an entirely new fuel reprocessing scheme will be deployed to process spent fuel. This new process will be based on a pyrochemical process similar to that shown in Figure 6 . This new process dramatically reduces the amount of secondary waste generated by fuel reprocessing.

The addition of fast reactors to the fleet provides the opportunity to use other fuel cycles. The leading candidate for an alternate fuel cycle is the thorium fuel cycle. ${ }^{11}$ The interesting aspect of the thorium cycle is that it does not produce plutonium during the first cycle (see Figure 7). Subsequent recycles produce plutonium, but primarily the 238 isotope, which makes the material very hazardous to handle and impossible to process using aqueous processes, such as PUREX. Although uranium 235 is required to drive the first cycle, subsequent cycles are driven by fission of uranium 233.

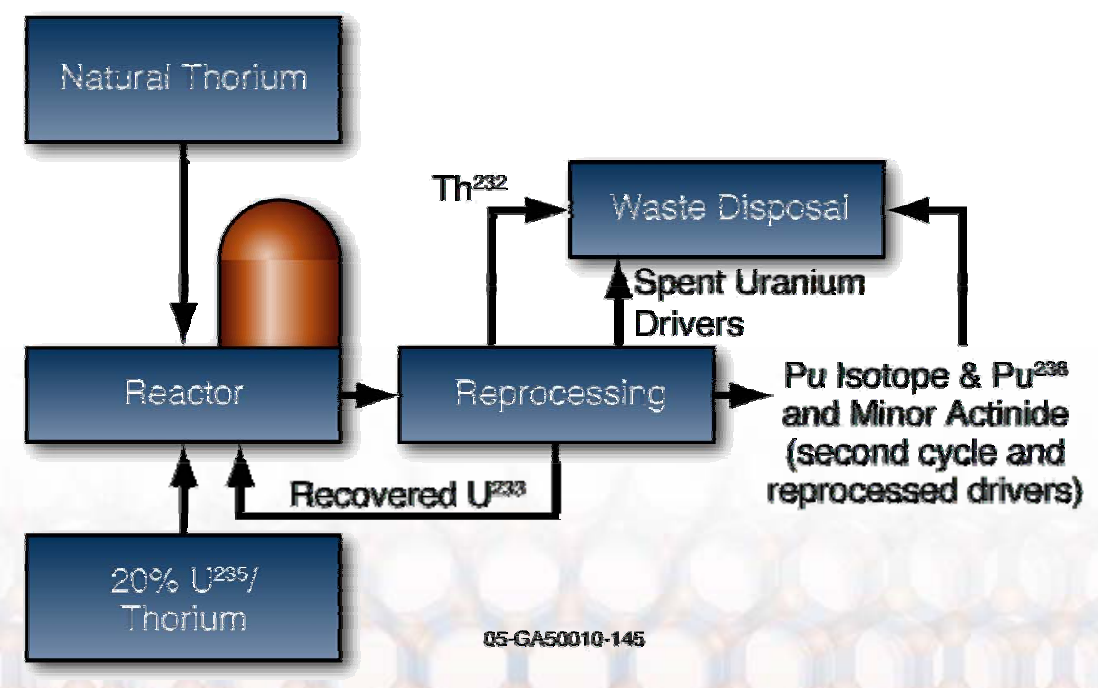

Figure 7. Thorium fuel cycle. 
Several technical challenges are associated with the fully closed fuel cycle. No pyrochemical processes currently exist that have the desired separation efficiencies. Transmutation and accelerator driven reactors have not been demonstrated. Transmutation of technetium and iodine has not been shown to be feasible. Although considerable research is underway in India, viable thorium reprocessing schemes have not been developed or tested on any significant scale.

\section{Approach}

- Develop and deploy pyrochemical fuel reprocessing

- Examine the feasibility of a thorium fuel cycle and subsequent reprocessing

- Employ computational chemistry approaches to development of advanced reprocessing methods for thorium

- Develop appropriate waste forms for thorium cycle waste

- Develop nuclear detection methods for monitoring proliferation aspects of uranium 233.

\section{Future SASR Capabilities}

- INL will have the pyrochemical expertise to explore the possibility of processing oxide materials

- INL will have the separation expertise needed to address issues associated with the process for separating uranium-233 from irradiated thorium (THOREX)

- INL will have the expertise to perform thorium extraction and separations research.

\section{Fuel Cycle Safeguards}

A robust safeguards research and development program is the single most significant technical investment that can be made to enhance the proliferation resistance of nuclear technology. Each fuel cycle facility type requires safeguards. Enrichment plants, fuel fabrication facilities, reactors, reprocessing plants, and waste storage need to be monitored. These safeguard actions present technical safeguard challenges. Technical safeguards refers to the technologies used both domestically and internationally to protect nuclear materials facilities from theft and to verify that the material and facilities are being used for peaceful purposes. Safeguards technologies are needed to detect concealed enrichment plants, production reactors, and reprocessing plants. Methods are needed to detect production of highly enriched uranium. More importantly, advanced technologies are needed to detect covert production of nuclear materials and uncover diversion of nuclear materials or undeclared use of facilities for production of special nuclear materials. Finally, advanced technologies are needed to detect diversion of nuclear materials and spent fuel.

\section{Approach}

- Support enhanced detection capabilities by developing higher resolution, lighter weight, lower power, room-temperature radiation detectors

- Support enhanced detection capabilities by developing unique fuel cycle facility process monitors

- Support non-proliferation activities by deploying faster, cheaper, environmental analysis methodologies

- Support non-proliferation activities by designing new methods for tagging nuclear materials for tracking and monitoring

- Support enhanced detection capabilities by developing new detection methods for real-time, on-scene data acquisition 
- Support enhanced detection capabilities by exploring novel, highly specific sorbents or elemental complexants coupled to appropriate sensors

- Support non-proliferation activities by dramatically extending detection limits for analytical techniques.

\section{SASR Capabilities}

- INL has an outstanding capability for analytical radiochemistry that has developed techniques and methods applicable to a range of unusual biological matrices for analysis of actinides and other radionuclides in environmental samples.

- INL has on-going research activities that support deployment of extremely sensitive isotopic analysis instrumentation that can be used for non-proliferation applications.

- INL has a unique capability associated with the design of high sensitivity mass spectrometers. This capability can be mobilized to support safeguard technology needs. 


\section{SITUATIONAL ANALYSIS}

The purpose of this discussion is to review the programs and INL research activities and other institutions related to separations and actinide science. The review indicates research areas where gaps may exist and identifies potential collaborators with well established research efforts.

\section{Programmatic History and INL Research}

Since the mid-1970s there has been very little research related to commercial fuel reprocessing in the U.S. Basic research investments related to separation and heavy element chemistry have been made by SC. SC annually invests approximately $\$ 10$ million in the combined areas of separations and heavy element chemistry, and this amount has been either static or declining in recent years. Weapons-related plutonium research sponsored by DOE-Defense Programs and later by National Nuclear Safety Administration has continued to receive stable funding and has maintained strong research activities at the weapons laboratories. In the early 1990s, the increased interest in cleaning up the nuclear weapons production legacy resulted in research being sponsored for processing of high-level wastes. The Separations Cross-cut program provided a significant amount of funds for fundamental and applied research and process development. At the time that the Separations Cross-cut program was ending, the high-level waste focus area and EMSP continued to sponsor actinide chemistry and separations research. These environmental management sponsored programs were primarily focused on waste located at Savannah River and Hanford sites. SC-sponsored research and some limited activities within the AFCI are ongoing.

In support of these programs and INL fuel processes, INL developed expertise in six Separations and Actinide Science areas:

- Actinide environmental chemistry

- Actinide radio-analytical chemistry

- Radiochemistry

- Aqueous separations

- Pyrometallurgy

- Fuels development.

To continue to support these areas, INL needs to increase the number of staff members working these areas, thus, adding depth and additional expertise to supplement the existing staff.

INL does have a number of well maintained hot cells and glove boxes containing equipment that supports fuel pin prototyping, fabrication, and pyrometallurgical processing of spent fuel. In addition, the INL has several unique facilities and pieces of equipment for materials testing, characterizing actinides on surfaces, and separation process development.

Recently, INL's actinide science, separations, fuels, and pyrometallurgy expertise was consolidated and now includes experts in Experimental Breeder Reactor II (EBRII) fuel processes. To supply the EBRII with experimental fuel, a capability to fabricate plutonium-containing fuel was established. Although metallic fuel was the primary product of this fabrication capability, ceramic and other specialized fuels were fabricated. To support decommissioning the EBRII, a dry process based on pyrometallurgical processing of the fuel was deployed. A molten salt pyrometallurgical process was used to recover heavy metal (uranium and plutonium) from driver and blanket fuel assemblies. The technical expertise to maintain this process is now performing research for the advanced fuel cycle to determine if a similar process can be used to process commercial reactor fuel. 
Additionally, much of the expertise currently at the laboratory was involved in environmental cleanup activities. To support environmental activities and other program needs, a radio-analytical chemistry capability was created. This capability is now nationally recognized for characterization of low concentrations of radionuclides and actinides in various types of environmental matrices, primarily living tissue.

Once reprocessing ended in Idaho, the separations and process capabilities were maintained because all the Idaho waste was acidic, opposed to the case of the waste at Hanford and Savanna River. The Universal Solvent Extraction Process and Acid Side Fission Product Extraction Process were developed by this group, as well as numerous first-time demonstrations of separation technologies on radioactive material.

\section{Need for Updated Facilities}

INL currently does not have sufficient radiochemical laboratories to support a nuclear energy and fuel reprocessing mission. Most of the INL facilities were constructed in the late 1950s to mid-1960s. These facilities have been expensive to maintain and have not received the necessary funding to maintain a high level of operability. Currently, about three-quarters of the available radiochemical laboratory space is scheduled to be decommissioned sometime after 2007. The process development laboratory was decommissioned and demolished in 2004. Currently the INL has no facility where process flowsheets can be tested on semi- or full-scale hot steams.

\section{Unique Equipment}

INL has one of the few operating material test reactors in the world. The design of this reactor facilitates materials testing, reactor fuel development, neutron activation, and other activities requiring high fluxes of thermal neutrons.

Unique surface science and mass spectroscopy instrumentation at INL permit characterization of actinides on surfaces of any type of material. Depending on the instrument, substrate surface temperatures can be varied from room temperature to greater than $1000^{\circ} \mathrm{C}$. Further, a number of specialized mass spectrometers are available or are currently under construction that permit extremely high resolution at mass values comparable to actinide elements.

An extensive scale-up and testing capability exists at INL and is used for solvent extraction flowsheet development. A number of units are capable of counter-current flows of approximately 2 to $19 \mathrm{~L} / \mathrm{min}$. A similar but smaller train exists in a hot cell for pilot runs associated with radioactive simulants or dissolved fuel.

There are a number of specialized glove boxes certified for handling transuranic materials. Equipment in these glove boxes allows for metal melting, welding, powder pressing, and similar activities.

\section{Other National Laboratories}

An assessment of the separations and actinide science capabilities at other national laboratories is shown in Figure 8. The greatest amount of actinide science capability exists at Los Alamos and Livermore. The activities at these laboratories have been maintained to support weapons-related activities, although these capabilities can be applicable to a range of topics. The staffing, facilities, and equipment at these two laboratories are world-class. Most of the separations expertise resides at Oak Ridge National Laboratory and Argonne National Laboratory. However, due to the environmental management focus of these activities and loss of expertise over time, these capabilities have been declining. Computational and theoretical capabilities exist at Pacific Northwest National Laboratory, Oak Ridge, Los Alamos, and Livermore National Laboratories. Los Alamos and Livermore are strong in capabilities related to molecular dynamics and quantum mechanics. Pacific Northwest and Oak Ridge have strong capabilities related to applications and code development. 


\begin{tabular}{|l|c|c|c|c|c|c|c|}
\hline \multicolumn{1}{|c|}{$\begin{array}{c}\text { Separations and Actinide } \\
\text { Chemistry Capabilities }\end{array}$} & LANL & LLNL & ORNL & ANL & PNNL & BNL & INL \\
\hline Separations & & & & & & & \\
\hline Flowsheet development & $\mathbf{X}$ & & $\mathbf{X}$ & $\mathbf{X}$ & & & $\mathbf{X}$ \\
\hline Process development & $\mathbf{X}$ & & $\mathbf{X}$ & $\mathbf{X}$ & & & $\mathbf{X}$ \\
\hline Radiological process development & $\mathbf{X}$ & & & $\mathbf{X}$ & & & \\
\hline Complexant design-basic & $\mathbf{X}$ & & $\mathbf{X}$ & & $\mathbf{X}$ & & \\
\hline Complexant design-acidic & & & $\mathbf{X}$ & & & & $\mathbf{X}$ \\
\hline Supercritical extraction & $\mathbf{X}$ & & & & & & $\mathbf{X}$ \\
\hline Pyrochemical separations & $\mathbf{X}$ & & & $\mathbf{X}$ & & & $\mathbf{X}$ \\
\hline Molten salt electrochemistry & $\mathbf{X}$ & & & $\mathbf{X}$ & & & $\mathbf{X}$ \\
\hline Pyrometullurgy & $\mathbf{X}$ & & & & & & $\mathbf{X}$ \\
\hline Actinide Chemistry & & & & & & & \\
\hline Fundamental F-element chemistry & $\mathbf{X}$ & $\mathbf{X}$ & & $\mathbf{X}$ & $\mathbf{X}$ & $\mathbf{X}$ & \\
\hline Environmental actinide chemistry & $\mathbf{X}$ & & & & $\mathbf{X}$ & & $\mathbf{X}$ \\
\hline Actinide interfaces-Matl's aging & $\mathbf{X}$ & $\mathbf{X}$ & & & & & \\
\hline Actinide analytical chemistry & $\mathbf{X}$ & & & & $\mathbf{X}$ & & $\mathbf{X}$ \\
\hline Actinide complexes at interfaces & & $\mathbf{X}$ & & $\mathbf{X}$ & & & \\
\hline Colloidal chemistry & & $\mathbf{X}$ & & & & & $\mathbf{X}$ \\
\hline Plutonium aging & $\mathbf{X}$ & & & & & & \\
\hline Spectroscopy & $\mathbf{X}$ & & $\mathbf{X}$ & $\mathbf{X}$ & & & \\
\hline Photochemistry & $\mathbf{X}$ & & & $\mathbf{X}$ & & & \\
\hline
\end{tabular}

05-GA50010-150

Figure 8. Separations and actinide chemistry capabilities across the DOE complex.

\section{Universities}

University capability in separations and actinide science can be characterized as involving a single investigator or faculty member. These capabilities are spotty and have been declining in recent years due to reduced interest in radiochemistry and actinide chemistry. The institutions with long-standing actinide science and actinide separations include Florida State (Greg Choppin now retired), Washington State (Ken Nash and Sue Clark), University of New Mexico (Robert Paine), and University of Nevada at Las Vegas (Ken Czerwinski).

\section{International Institutions}

Separations and actinide science have continued to be topics of interest at international institutions due to the fact that spent fuel reprocessing has continued in the United Kingdom, France, and Russia. Activities at Atomic Weapons Establishment and at Sellafield in the United Kingdom have continued to support research and development related to the aqueous process. New radiochemical laboratories at Sellafield and University of Manchester were recently dedicated to investigate phenomena related to separation associated with waste and spent nuclear fuel. Research activities at Commissariat a l'Energie Atomique have also been a large contributor to new processes and separation schemes. Pyrochemical processing of spent fuel and activities related to development of a thorium fuel cycle have been progressing at the Bhabha Atomic Research Centre in India. The INL has had a long standing collaboration with the Khlophin Radium Institute related to actinide and fission product separations. Fuel cycle development research and development has been progressing at the Japanese Atomic Energy Research Institute. Similarly, pyroprocess development has been proceeding at the Central Research Institute of Electric Power Industry in Korea. In total there are over 100 institutions performing actinide and separations related activities, worldwide. 


\section{PATH FORWARD}

As discussed in the previous sections, a Separations and Actinide Science program is critical to the success of INL. To be recognized as the leader in nuclear research and technology, INL needs to establish world-class capabilities. A world-class capability is one that is recognized to have superb and renowned people, unique and modern facilities, one-of-a-kind instrumentation and equipment, and broadly sponsored work. This section describes a path by which the current laboratory resources are transformed over the next 10 years into a world-class research capability.

\section{Staff}

INL has a small number of senior researchers in Separations and Actinide Science. Some of these people are highly respected in their area of expertise. However, most are not recognized by the nuclear research community, since they have focused recently on environmental topics. There are six strategies related to acquiring and retaining the right people.

Strategy 1: Focus existing technical staff to work on nuclear technology-related activities and ensure publication in nuclear community technical journals.

Strategy 2: Recruit a world-recognized leader in Separations and Actinide Science.

Strategy 3: Make strategic hires to gain increased expertise in separations, pyrochemistry, and actinide chemistry. Initial hires will be senior researchers with significant expertise. Later hires will be composed of a mid- and early- career researchers.

Strategy 4: Establish strategic collaborations with leading research institutions to obtain participation of domestic and foreign researchers in INL projects. Once a robust research activity is established, these collaborations will provide a mechanism for gaining unique expertise, new ideas, and access to an emerging work force, as represented by graduate students.

Strategy 5: Implement a post-doctoral fellowship program that will provide a constant stream of bright young scientists and engineers to work on nuclear technology issues.

Strategy 6: Create a staff sabbatical program that will provide a three- to six-month paid leave to staff with ten or more years of service. Sabbatical leave will allow INL researchers the opportunity to work at other institutions throughout the world. This leave will provide a mechanism for invigorating the existing work force.

\section{Facilities}

With facility decommissioning actions slated for 2008 , there is a significant need to get new facilities to perform mission-related actinide research. In broader terms, most of the research facilities in this country, with the exception of the plutonium and materials laboratories at Los Alamos and the New Mexico State Laboratories in Carlsbad, New Mexico, are old and antiquated. The number of laboratories and sites in the U.S. where researchers can access and work with actinide elements is extremely limited.

Five strategies are presented to rectify the lack of availability of modern facilities for nuclear technology research and for development of a national resource for collaborative research and development activities. The strategies need to be implemented immediately since the radiochemical laboratories located at the Reactor Technology Complex (RTC) will be closed in 2008. 
Strategy 1: Construct a small replacement laboratory at RTC to support reactor needs and provide limited support to programs

Strategy 2: Work with DOE-ID to replace the current INL Research Center (IRC) radiological limits with limits similar to those applicable for research at local universities

Strategy 3: Upgrade the IRC fume hood system to accommodate radiological research involving lowactivity levels

Strategy 4: Construct a radiological laboratory at Materials and Fuel Complex (MFC) capable of limited process development and modest-activity level research

Strategy 5: As part of the AFCI program, construct a large process development laboratory and radiochemical research laboratory to support advanced fuel cycle development efforts and to serve as a user facility for actinide studies

Strategy 6: Establish Memorandum of Understanding and collaborations with other national laboratories and universities so that INL can gain access to facilities at these locations.

\section{Equipment}

In order to perform fuel cycle research and development, state-of-the-art instruments, such as nuclear magnetic resonance spectrometers, laser-based fluormeters, inductively coupled mass spectrometers, inductively coupled atomic emission spectrometers, gas chromatographs, mass spectrometers, and other pieces of advanced instrumentation must be available in environments where radioactive materials can be handled. This equipment is needed for laboratories, and for use inside of glove boxes and hot cells.

One-of-a-kind pieces of instrumentation are the hallmark of a world-class institution. Capabilities, such as a synchrotron light source or pulsed neutron source, are examples of this type of one-of-a-kind device. An example of such a piece of equipment applicable to actinide science and separations is the advanced Trapped-Ion Mass Spectrometer. This instrument will have an advanced ion trapping and isolation capability, which, combined with both collisional and photo-excitation, will enable highly controllable ion dissociation studies. This instrument will provide unparalleled validation capability for computation research efforts and will be able to generate clusters and complex molecules under highly controlled conditions necessary to aid in accurate prediction of extraction performance and material properties.

Availability and sophistication of equipment at national laboratories is one of the reasons that the best researchers are attracted to these institutions. If INL is to become world-class, the very best and most advanced equipment must be available to its researchers. Given the fact that there has been little investment in new equipment over the past several years, it is critical that steps be taken to rectify this problem. The following strategies are designed to obtain this needed equipment.

Strategy 1: Based on analysis of the best-in-class institutions performing separations and actinide science, develop a list of routine, unique, and one-of-a-kind instruments needed for research and development activities. Establish a priority for each item using criteria designed to most critical items.

Strategy 2: All new SASR proposals and Field Work Packages will include the purchase of new equipment.

Strategy 3: Purchase one high-value item per year. 
Strategy 4: Identify equipment at other research institutions and develop collaborations to gain access to the equipment. Based on results obtained, demonstrate the value of these types of measurements or analyses to the laboratory mission(s).

Strategy 5: Develop proposals to NE and NA for acquisition of unique or one-of-a-kind pieces of equipment needed to support their missions.

Strategy 6: Pursue cost-sharing arrangements to fund development, purchase, or construction of one-of-a-kind instruments. Once the instrument is operational, surround it with support capabilities and offer access to external researchers.

\section{Collaborations}

A large amount of technical capability related to separations and actinide science exists externally. Collaboration is a useful mechanism to leverage this existing capability to enhance INL's effectiveness. Collaboration accomplishes the following:

- Provides external knowledge and consultation to grow INL staff capabilities and understanding of methods and technology

- Builds recognition with peer-groups and the related research community

- Creates a mechanism to import knowledge and retrain staff

- Opens an avenue to hire future staff.

Broadly speaking, collaborations not only occur with parties outside the laboratory, but also need to occur between organizations, distinctive signatures, and centers within the laboratory. There are various mechanisms that can be used to establish key collaborations. In general, most collaborations are between individual researchers and are driven by familiarity. In areas where the laboratory lacks a specific capability, strategic collaborations can be created by joint proposals, sub-contracts, and through access to specialized facilities. Other mechanisms for formation of collaborations are the joint sponsorship of workshops and symposia and participation in alliances and consortia.

\section{External Collaborations}

Based on the information in the situational analysis, the following partners are suggested.

- Los Alamos - Actinide chemistry and computational chemistry

- Oak Ridge - Extractant characterization and thermodynamics

- Pacific Northwest - Modeling of complexation

- Washington State University - Actinide and lanthanide separation

- University of Nevada Las Vegas - Actinide chemistry

- Colorado School of Mines - Materials fabrication and molten salt electrochemistry

- Australia Nuclear Science and Technology Organization - Adsorbents and ion exchange

- Khlophin Radium Institute - Actinide and fission product separations

- Central Research Institute of Electric Power Industry - Pyroprocessing

- Institute for Transuranium Elements - Fuels chemistry

- Commissariat a l'Energy Atomique - Actinide and lanthanide separations. 


\section{Internal Collaborations}

This distinctive signature will also need to collaborate with other signatures, centers, and organizations within INL. Since the Materials and Nuclear Fuel Signature shares an interest in fuel chemistry, collaboration with this activity will be needed to maximize INL capabilities. One of the strategies of the Center for Advanced Modeling and Simulation (CAMS) is to support the computational needs of actinide science. To maximize the usefulness of code development, acquisition of codes, and other computational infrastructure, the Separations and Actinide Science signature needs to work closely with CAMS to ensure needs are articulated. At present, no actinide science computational expertise exists at INL. A multiparty collaboration between this signature, CAMS, and Los Alamos will be needed to develop this capability at INL.

Collaborations with other signatures will occur on topics of mutual interest. Since advanced detection schemes are needed for a range of applications, close collaboration between actinide chemistry, sensor/detector developers in the Reactor and Nuclear Physics organization, and the Instrumentation, Control, and Intelligent Systems Science Signature will be needed. A number of internal collaborations beyond, those mentioned, will be created.

The following strategies will help accomplish the necessary advancements in collaboration:

Strategy 1: Develop a joint research program with Washington State University

Strategy 2: Develop a joint research program with the University of Las Vegas (UNLV)

Strategy 3: Renew the collaboration with the Khlophin Radium Institute

Strategy 4: Develop a joint research activity related to computational chemistry with Los Alamos.

\section{Programmatic Funding}

The strategies presented in this roadmap cannot be implemented without significant new programmatic funding. Since the roadmap envisions revitalizing not only INL but the entire separations and actinide science community, the business development strategies presented must be all-inclusive. As was discussed previously, the only funding available to this community, that is not defense related, is from SC and a very limited amount of funding from the AFCI program. This situation needs to be dramatically changed to address the technical needs and challenges posed by fuel reprocessing.

There are three distinct elements to the business strategy: establish an applied research program at INL, revitalize the Nuclear Engineering Research Initiative (NERI), and create a basic science program that competitively funds relevant research.

To build the needed technical infrastructure required to support the Separations and Actinide Science Signature, NE needs to fund a nuclear energy applied research program at INL. All research activities performed within this program will be directed to near- and mid-term technology needs. Projects will be selected by competitive proposal from INL participants. Successful proposals will need to have external collaborators and pass a peer-review composed of primarily external program personnel. Additionally, this program will provide the staff and facilities needed to solve technology problems arising during technology demonstration activities.

The existing NERI program needs to be restructured and refocused on relevant NE technology needs. This funding mechanism will serve to provide the applied research funding to the external research community. Project requirements for collaboration, peer-review, and mission relevance will be similar to those of the INL internal program. 
New concepts, ideas, and approaches are needed to solve many of technical needs and challenges. Basic research is the source of these solutions. However, unfettered fundamental science is not what is required and more problem-oriented research is necessary. An outstanding model for this basic research program is the extremely successful EMSP process. EMSP is a unique program where management of the research was shared between the SC and Office of Environmental Management (EM). Funding and relevance is provided by EM and research quality and oversight is provided by SC. EMSP is very popular with the research community, program office, and Congress. The suggested program extends beyond both INL and the technical activities of the signature. The strategies related to obtaining funding for this program are focused on championing the idea and providing coordination of the laboratory's position related to the program. Should the program be realized, SASR would provide a platform to coordinate the proposal response to proposal calls.

The programmatic funding strategies are:

- Develop a five-year business plan

- Identify a relationship manager for NE

- Develop a proposal to sponsor the applied research program at INL and submit to AFCI

- Reformulate the NERI program

- Develop Nuclear Energy Science Program (NESP)

- Support development of proposal responses to NESP

Figure 9 shows near-, mid-, and long-term strategies for staff, facilities, equipment, collaborations, and programs to achieve the Separations and Actinide Science vision.

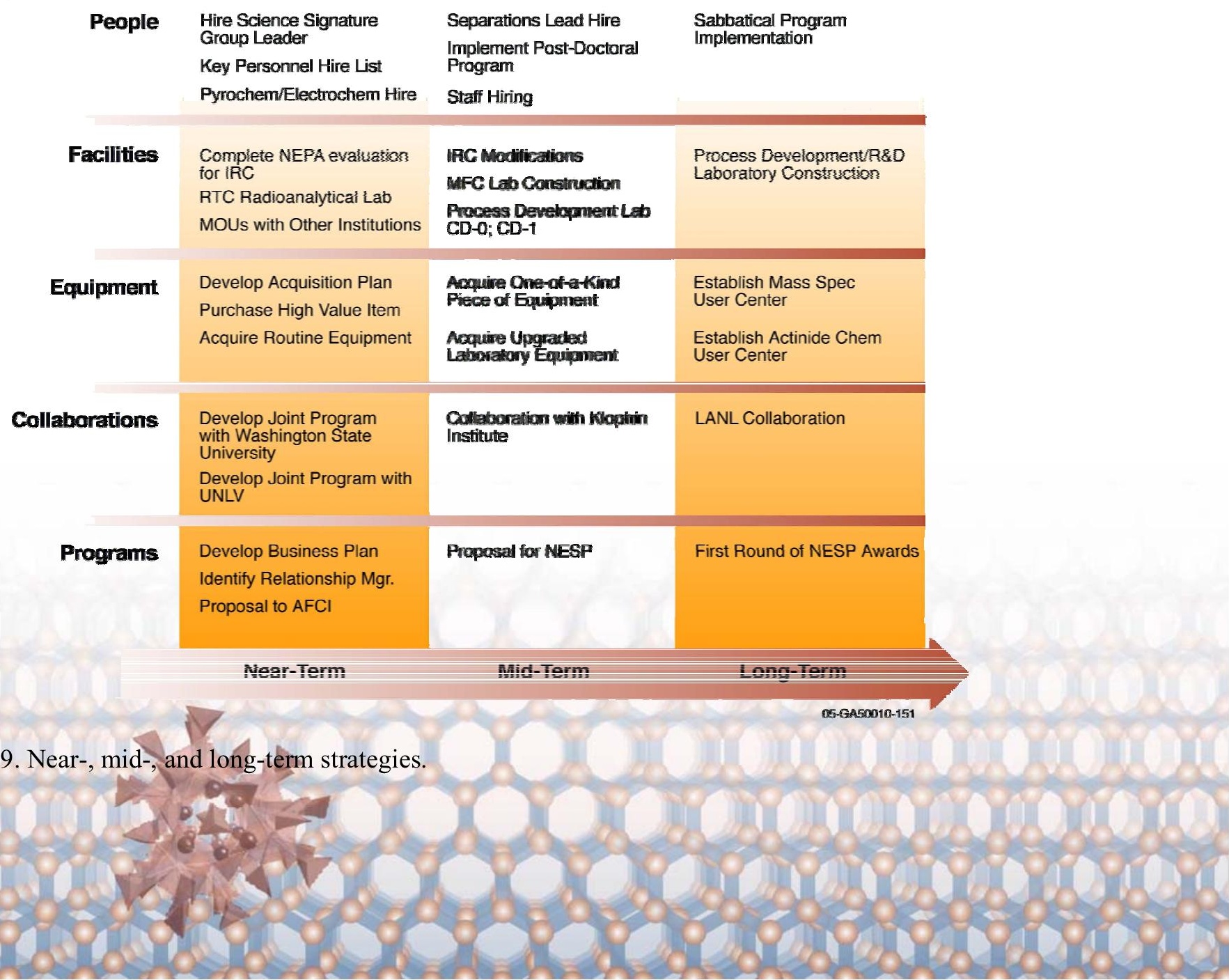




\section{SUMMARY AND RECOMMENDATIONS}

The Separations and Actinide Science Roadmap presents a vision to establish a SASR base composed of staff, facilities, and collaborations to provide new and innovative solutions to nuclear technology issues and to preclude nuclear proliferation. This roadmap does not provide quick fixes to nuclear technology challenges, but provides a 10-year journey to build a strong SASR technical capability with a clear mission to support nuclear technology development.

The challenges to extensive deployment of nuclear technology primarily revolve around the issues associated with the nuclear fuel cycle. Without an advanced fuel cycle, nuclear energy will not be sustainable, but the technical challenges associated with an advanced fuel cycle are substantial. A strong capability in Separations and Actinide Science is pivotal to finding solutions to these technical challenges.

Separations and actinide science capabilities at INL, and to some extent for the entire domestic technical community, can be summarized as being insufficient to effectively address the technical issues associated with the nuclear fuel cycle. Unique facilities and technical talents needed to perform the necessary research and development activities are limited. With exception of the weapons laboratories, those domestic institutions that do have capacity to perform this research have old and outdated facilities. INL urgently needs new facilities to perform laboratory research and process development as available facilities will be decommissioned in a few years.

Capabilities exist both in the U.S. and abroad for separations and actinide science. Collaboration between INL and these other institutions will help to jump-start and fortify INL's activities, provide access to a substantial knowledge base, gain access to specialized research tools, train and retain INL staff, provide a forum for nuclear detection and radiochemical separations dialogue, and provide access to potential future staff.

The success of this roadmap depends on obtaining the programmatic funding to acquire staff, facilities, equipment, and collaborations. Funding is needed at INL for both basic and applied research activities directed at the technical issues associated with the fuel cycle. This roadmap gives a number of strategies to obtain this funding.

Lastly, this roadmap makes three recommendations related to programmatic actions that must occur to renew domestic separations and actinide science capabilities. NE should fund substantial applied research at INL to create a knowledge base for deployment of new fuel cycle technologies. The NERI program should be revamped and redirected to support applied research in the research community external to INL. An nuclear energy basic science program modeled after EMSP, with shared management between SC and NE, should be created to address the long-term technical issues and to foster training of the future generation of nuclear technology scientists and engineers. 


\section{REFERENCES}

1. Deutch, J. and Moniz, E. J., (2003) “The Future of Nuclear Power: An Interdisciplinary MIT Study”, Massachusetts Institute of Technology.

2. Committee on Science and Technology for Counter Terrorism, (2002) "Making the Nation Safer: The Role of Science and Technology in Countering Terrorism", The National Academy of Sciences.

3. Tomero, L. (2005), "Implications of Commercial Spent Fuel Reprocessing," testimony for House Subcommittee on Energy, June 8.

4. Nuclear Study Group, (2005), "Nuclear Power and Proliferation Resistance: Securing Benefits, Limiting Risks," American Physical Society Panel on Public Affairs.

5. von Hippel, F.N. (2001), Science 293, 2397-2398.

6. Lovins, A. B, (1980), Nature 283, 5750, 817-823.

7. U.S. Department of Energy, Office of Nuclear Energy, Science and Technology, (2005) Advanced Fuel Cycle, Comparison Report.

8. Carlson, J., J. Bardsley, V. Gragin, J. Hill, (1997) "Plutonium Isotopics - Non-Proliferation and Safeguards Issues", IAEA-SM-351/64.

9. Porsch, D., W. Stach, P. Charmensat, M. Pasquet, (2005), Nuclear Technology 151, 159-167.

10. Vandergrift, G. F., etal. (2004) "Design and Demonstration of the UREX+ Process Using Spent Nuclear Fuel,” Atalante 2004, Nimes, France, June.

11. Galperin, A., Reichert, P., Radkowsky, A. (1977), Science and Global Security 6, 265-290. 
